\title{
LICITAÇÕES SUSTENTÁVEIS: UM INSTRUMENTO PARA A CONCRETIZAÇÃO DO DIREITO FUNDAMENTAL À BOA ADMINISTRAÇÃO PÚBLICA*
}

\author{
Susan de Melo Marinho** \\ Rogério Santos Rammê***
}

\section{RESUMO}

O processo licitatório foi instituído pela Lei 8.666/93 e teve sua redação atualizada em 2010 pela lei 12.349 estabelecendo que além de assegurados os princípios da isonomia e da proposta mais vantajosa, seja considerada a promoção do desenvolvimento nacional sustentável. Esta atualização se deu, pois o legislador percebeu a necessidade em promover a sustentabilidade, tendo em vista a crescente crise ambiental em que se encontra o planeta. Como é responsabilidade do Estado fazer cumprir o direito de todos os cidadãos a um meio ambiente sadio consolidado pelo artigo 225 da CF/88, foi ressaltado: o direito à boa administração pública. O estudo trará considerações sobre o papel da Administração Pública na gestão eficiente dos recursos financeiros e naturais, analisará de forma comparativa o texto da Lei das Licitações antes e após sua atualização e demonstrará de forma prática de que forma vem sendo aplicada a legislação pelos Poderes. A abordagem do tema não apenas é necessária do ponto de vista da melhor observação do princípio da boa administração pública, mas também no âmbito da função social que as compras públicas devem ter. A sustentabilidade não é um princípio que pode ser objeto

* Artigo apresentado ao Curso de Bacharelado em Direito do Centro Universitário Metodista - IPA, como requisito parcial para obtenção do Grau de Bacharel em Direito.

** Graduanda do Curso de Bacharelado em Direito do Centro Universitário Metodista - IPA.

*** Orientador do Artigo. Professor do Curso de Bacharelado em Direito do Centro Universitário Metodista - IPA. Doutor em Direito pela PUCRS. Mestre em Direito Ambiental pela UCS. 
da discricionariedade do administrador. É norma cogente e positivada, vinculando o agente ao seu devido cumprimento.

Palavras-chave: Sustentabilidade. Licitações públicas. Desenvolvimento sustentável. Administração Pública. Direito fundamental. Interesse público. Licitações sustentáveis.

\section{SUSTAINABLE BIDDINGS: AN INSTRUMENT FOR THE REALIZATION OF THE FUNDAMENTAL RIGHT TO GOOD PUBLIC ADMINISTRATION}

\section{ABSTRACT}

The bidding process was instituted by the Law 8.666/93 and was updated in 2010 by Law 12,349, establishing that in addition to ensuring the principles of isonomy and the most advantageous proposal, consideration should be given to the promotion of sustainable national development. This update occurred because the legislator realized the need to promote sustainability, given the growing environmental crisis in which the planet is. As it is the responsibility of the State to enforce the right of all citizens to a healthy environment consolidated by article 225 of CF / 88, another right was emphasized: the right to good public administration. The study will consider the role of the Public Administration in the efficient management of financial and natural resources, will analyze in a comparative way the text of the Law of Biddings before and after its updating and will demonstrate in a practical way how the legislation is being applied by the Powers. The approach to the subject is not only necessary from the point of view of better observance of the principle of good public administration, but also within the social function that public procurement should have. Sustainability is not a principle that can be the object of the administrator's discretion. It is a cogent norm, binding the agent to its due fulfillment.

Key words: Sustainability. Public bids. Sustainable development. Public administration. Fundamental right. Public interest. Sustainable bids.

\section{INTRODUÇÃO}

0 presente trabalho tem por tema principal o processo licitatório, mais especificamente as licitações sustentáveis e sua importância para a efetivação do direito fundamental à boa administração pública. No que concerne às licitações, procuraremos 
estabelecer quais os critérios para sua realização e a importância do caráter sustentável que elas devem ter quando expostas à luz da boa administração pública.

Considerando que a Lei 12.349/2010 alterou o art. 3ํ da Lei 8.666/93, incluindo dentre as finalidades das licitações a promoção do desenvolvimento nacional sustentável, indaga-se, como problema de pesquisa, de que modo as licitações podem promover uma conciliação entre desenvolvimento e sustentabilidade e qual relação existente entre as licitações sustentáveis e aquilo que a doutrina passou a denominar de "direito fundamental à boa administração pública"?

O processo licitatório foi instituído em 1993 pela Lei 8.666, delimitando as aquisições de bens e serviços pela Administração Pública apenas por este formato, salvo hipóteses específicas de dispensa, dispensabilidade e inexigibilidade, previstas nos artigos 17, 24 e 25 da referida lei federal. Foi aprimorado em 2010 pela Lei 12.349 que, dentre outras regras, estabeleceu que além de serem assegurados os princípios da isonomia e da proposta mais vantajosa, fosse considerada a promoção do desenvolvimento nacional sustentável.

A preocupação do legislador em considerar a sustentabilidade como requisito norteador das compras públicas surgiu com a percepção da necessidade, não apenas da proteção do meio ambiente, mas também de tornar o processo licitatório mais social e economicamente sustentável.

A boa administração pública é direito fundamental de todos os indivíduos e sua concretização se dá pela gestão eficiente dos atos administrativos praticados, otimizando-os e procurando alcançar sempre a finalidade do interesse público como primeira medida.

0 interesse público tem de ser a única finalidade dos atos administrativos de qualquer um do Três Poderes. Não há que se falar em discricionariedade neste ponto, pois resguardar o interesse de toda a coletividade é obrigação dos agentes admi- 
nistrativos, está vinculada à lei apesar de qualquer hermenêutica que possa ser aplicada.

Desta forma, o objetivo geral deste artigo é analisar a relação entre as licitações públicas e a sustentabilidade no que tange à sua aplicação como princípio balizador e primordial para a concretização da boa administração pública enquanto direito fundamental.

Como objetivos específicos da presente pesquisa, tem-se: analisar o direito fundamental à boa administração pública e sua relevância dentro das licitações em geral; caracterizar e analisar o processo licitatório quanto ao seu regime jurídico desde sua instituição em 1993 até sua modificação e inovações em 2010; analisar e identificar a importância do princípio da sustentabilidade no processo licitatório brasileiro, e determinar a relevância das licitações sustentáveis para a concretização do direito fundamental à boa administração pública.

A pesquisa buscará realizar uma análise doutrinária e jurisprudencial com o intuito de possibilitar o entendimento do que se trata a sustentabilidade na atualidade, bem como demonstrar a importância da boa administração pública enquanto direito fundamental de todos os indivíduos.

A preocupação com um meio ambiente sadio e sustentável não pode mais ser exclusividade de apenas um pequeno grupo da sociedade que o defende, mas deve ser uma consideração de toda a população, pois é dele que depende o futuro de todos enquanto seres humanos. Dessa forma, a licitação pública trata-se, acima de todas as coisas, de política pública para a proteção não apenas do meio ambiente, mas do desenvolvimento das pessoas, contribuindo para o despertar de uma ecocidadania, de modo a harmonizar os deveres de proteção constitucionalmente impostos ao Estado e à cada indivíduo da coletividade em matéria de proteção do meio ambiente.

A narrativa foi estruturada do seguinte modo: inicialmente analisa-se o conceito e a natureza jurídica do direito fundamental 
à boa administração pública. Na sequência a análise se volta ao regime jurídico das licitações no ordenamento jurídico brasileiro e à modificação legislativa havida no processo licitatório a partir de 2010, com enfoque na sustentabilidade, analisando também jurisprudências à vigência da nova redação. Ato contínuo, a pesquisa analisa o princípio da sustentabilidade, suas dimensões e aspectos históricos. Por fim, o trabalho procura demonstrar a essencialidade da sustentabilidade no processo licitatório para a concretização da boa administração pública enquanto direito fundamental.

Sem a pretensão de esgotar a matéria objeto desde estudo espera-se contribuir com aportes teóricos relevantes para o aperfeiçoamento do processo licitatório no Brasil com foco na proteção ambiental.

\section{O DIREITO FUNDAMENTAL À BOA ADMINISTRAÇÃO PÚBLICA}

0 artigo 225 da Constituição Federal prevê como direito de todos os cidadãos a proteção e desenvolvimento de um meio ambiente sadio e ecologicamente equilibrado, sendo dever do Estado proteger, controlar, fiscalizar e punir aqueles que vierem a transgredi-lo. Contudo, o poder/dever do Estado não é apenas de polícia, mas também de agente, atuante não apenas na proteção do desenvolvimento sustentável, mas em sua promoção.

Segundo Hely Lopes Meirelles ${ }^{1}$ o poder do agente público tem caráter de dever quando se trata da comunidade sobre a qual é responsável, obrigando-o a exercitá-lo independente de vontade, não podendo, inclusive, renunciá-lo. No mesmo sentido,

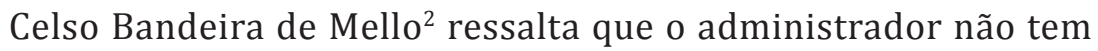

1 MEIRELLES, Hely Lopes; ALEIXO, Délcio Balestero; BURLE FILHO, José Emmanuel. Direito administrativo brasileiro. 40. ed. São Paulo, SP: Malheiros, 2013. p. 112.

2 MELLO, Celso Antônio Bandeira de. Curso de direito administrativo. 31. ed. São Paulo, SP: Malheiros, 2014. p. 77. 
o direito de dispor dos interesses públicos à sua mera vontade. Pelo contrário, é obrigado a assegurá-los e garantir que tenham sua finalidade alcançada.

Assim também leciona José dos Santos Carvalho Filho ${ }^{3}$ :

As prerrogativas públicas, ao mesmo tempo em que constituem poderes para o administrador público, impõem-lhe o seu exercício e lhe vedam a inércia, porque o reflexo desta atinge, em última instância, a coletividade, esta a real destinatária de tais poderes.

Na mesma seara, a Administração Pública tem de observar primordialmente a supremacia do interesse público sobre os direitos individuais, pois é ela que "vincula a autoridade em toda sua atuação" ${ }^{4}$ desde a elaboração da lei até sua execução pelo Administrador.

O princípio da supremacia do interesse público confunde-se muito com o princípio da finalidade dos atos administrativos, não sem razão. 0 interesse público tem de ser a única finalidade dos atos administrativos de qualquer um do Três Poderes. Não há que se falar em discricionariedade neste ponto, pois resguardar o interesse de toda a coletividade é obrigação dos agentes administrativos.

Marçal Justen Filho ${ }^{5}$ contrapõe alegando que os direitos subjetivos, principalmente os adquiridos são oponíveis tanto à lei quantos aos atos administrativos e que a "Constituição impõe que o sacrifício do direito subjetivo privado deve ser antecedido

3 CARVAlHO FILHO, José do Santos. Manual de direito administrativo / José dos Santos Carvalho Filho. 27. ed. rev., ampl. e atual. São Paulo, SP: Atlas, 2014. p. 46.

4 DI PIETRO, Maria Sylvia Zanella. Direito administrativo. 25. ed. São Paulo, SP: Atlas, 2012. 932 p..

5 JUSTEN FILHO, Marçal. Curso de direito administrativo. 4. ed. rev. atual. São Paulo, SP: Saraiva, 2009. p. 57. 
da indenização correspondente e adequada." Refere ainda o artigo 5ํㅜ XXXVI, da CF/1988 para ratificar sua afirmação de que os direitos subjetivos adquiridos não podem ser eliminados, nem restringidos, nem mesmo por lei posterior.

Coaduna com sua posição, o professor Juarez Freitas, ${ }^{6}$ ao declarar que não se pode mais invocar o interesse público para respaldar todo e qualquer ato administrativo, menosprezando os princípios e direitos fundamentais. Percebe-se nessa afirmação que o jurista se preocupa em não relativizar os direitos e garantias individuais em toda e qualquer circunstância em que o interesse público esteja em pauta.

O princípio do interesse público exige a subordinação das ações administrativas ao primados dos direitos fundamentais de todas as dimensões, notadamente do direito fundamental à boa administração pública. Não significa, portanto, acolher sobre pretexto algum, o inaceitável jugo da vontade particular imolada para gáudio de volúvel de falso interesse coletivo. ${ }^{7}$

No mesmo sentido, Odete Medauar, alega estar ultrapassado o princípio da supremacia do interesse público, tendo em vista a Constituição Federal de 1988 priorizar direitos fundamentais, e que é necessário ponderar interesses para que nenhum venha a ser sacrificado em detrimento do outro: "o objetivo desta função está na busca de compatibilidade ou conciliação dos interesses, com a minimização de sacrifícios."8

6 FREITAS, Juarez. 0 controle dos atos administrativos e os princípios fundamentais. 4 ed. São Paulo: Malheiros Editores, 2009, pg. 57.

7 Ibid., p.58

8 MEDAUAR, Odete. Direito administrativo moderno. 18. ed. rev. e atual. São Paulo, SP: RT, 2014.. ISBN 978-85-203-5123-9. p. 149. 
Maria Sylvia Zanella Di Pietro ${ }^{9}$ explica que apesar de existirem normas de direito privado que defendem o interesse público, bem como haja normas de direito público que defendam os direitos individuais, como a saúde, a segurança, a censura e até mesmo a propriedade, por exemplo - "as normas de direito público, embora protejam reflexamente o interesse individual, têm o objetivo primordial de atender ao interesse público, ao bem-estar coletivo."

Não trata-se, portanto, de desabrigar os interesses individuais em face dos coletivos, nem de suprimi-los quaisquer que sejam as situações, mas, sim de vincular os atos dos agentes administrativos ao que está amparado por lei e prestigiar de forma eficaz o bem-estar de toda a coletividade. E é nesse âmbito de apreciar a importância do interesse público que se encontra o princípio da boa administração.

A boa administração como direito fundamental foi consagrada na Carta de Direitos Fundamentais da União Europeia, em seu artigo 41, no ano de 2000 :

1.Todas as pessoas têm direito a que os seus assuntos sejam tratados pelas instituições, órgãos e organismos da União de forma imparcial, equitativa e num prazo razoável. 2. Este direito compreende, nomeadamente: a) 0 direito de qualquer pessoa a ser ouvida antes de a seu respeito ser tomada qualquer medida individual que a afete desfavoravelmente; b) 0 direito de qualquer pessoa a ter acesso aos processos que se lhe refiram, no respeito pelos legítimos interesses da confidencialidade e do segredo profissional e comercial; c) A obrigação, por parte da administração, de fundamentar as suas decisões.

9 DI PIETRO, Maria Sylvia Zanella. Direito administrativo. 25. ed. São Paulo, SP: Atlas, 2012. ISBN 978-85-224-6920-8. p. 85 
Já na Constituição Federal de 1988, este princípio é observado pelo artigo 37, no que tange a obrigatoriedade de eficiência dos atos administrativos. Diogo Figueiredo Moreira Neto ${ }^{10}$ aponta que a boa administração tem como balizadores a eficiência e os resultados de gestão, em que o primeiro caracteriza-se pela otimização dos meios administrativos aplicáveis, e o segundo pela idoneidade das ações do administrador no atendimento dos interesses públicos aos quais busca.

A boa administração, portanto, não é uma finalidade disponível, que possa ser eventualmente atingida pelo Poder Público: é um dever constitucional de quem quer que se proponha a gerir, de livre e espontânea vontade, interesses públicos. Por isso mesmo, em contrapartida, a boa administração corresponde a um direito cívico do administrado - implícito na cidadania. ${ }^{11}$

Carvalho Filho complementa o raciocínio ao definir que o dever da eficiência concentra-se em proporcionar que a atividade administrativa possua maior qualidade: "perfeição, celeridade, coordenação, técnica, todos esses são fatores que qualificam a atividade pública e produzem maior eficiência no seu desempenho."12

Cintia Morgado vai além, admitindo a boa administração pública não apenas como a concretização da melhor gestão, mas como um direto fundamental de todos os cidadãos. Relaciona as partes dogmática e orgânica das normas constitucionais, ou seja, os princípios de organização, estrutura e atuação com o reconhecimento de direitos que cabem à coletividade. Ela con-

10 MOREIRA NETO, Diogo de Figueiredo. Curso de direito administrativo: parte introdutória, parte geral e parte especial. 16. ed. rev. e atual. Rio de Janeiro, RJ: Forense, 2014. p. 118.

11 Ibid., p.117.

12 CARVALHO FILHO, José do Santos. Manual de direito administrativo. 27. ed. rev., ampl. e atual. São Paulo, SP: Atlas, 2014. ISBN 978-8522487417. p. 68 
clui afirmando que "isto explica que também seja denominado direito-garantia, pois conjuga ambos elementos, propiciando a defesa de outros direitos".13

Cumpre destacar que Juarez Freitas ${ }^{14}$ complementa o referido conceito de boa administração pública, estabelecendo que a discricionariedade do administrador não refere-se mais a sua faculdade de tomada de decisão, sopesando duas alternativas a partir de um juízo de conveniência e oportunidade, mas sim, de sua competência em escolher considerando todo o material fático e procurando sempre a solução mais eficiente na concretização do direito fundamental e de sua finalidade. Neste sentido, resume:

Numa frase, o direito à boa administração vincula racionalmente o gestor público e o força a medir consequências sistêmicas de suas opções, pois terá de justificá-las coerentemente, sobretudo em seu custo-efetividade. Examinado mais de perto, o direito fundamental é autêntico complexo de direitos, regras e princípios, encartados numa verdadeira síntese, que serve de antídoto contra o arbítrio (por ação ou por omissão).

Conclui-se, portanto, que a boa administração pública é direito fundamental de todos os indivíduos e que sua concretização se dá pela gestão eficiente dos atos administrativos praticados, otimizando-os e procurando alcançar sempre a finalidade do interesse público como primeira medida.

13 MORGADO, Cintia. Direito à boa administração. In: Revista da PGE, vol. 65, 2010.

14 FREITAS, Juarez. Políticas Públicas, Avaliação de Impactos e o Direito Fundamental à Boa Administração. Sequência (Florianópolis), Florianópolis , n. 70, p. 115-133, June 2015 . 


\section{O PRINCÍPIO DA SUSTENTABILIDADE: CONCEITO E DIMENSÕES}

A primeira demonstração de preocupação para com o meio ambiente e de consolidação deste como um direito-dever de todos os homens foi a Declaração de Estocolmo de 1972, notadamente em seu Princípio 8, no qual afirma-se: "O desenvolvimento econômico e social é indispensável para assegurar ao homem um ambiente de vida e trabalho favorável e para criar na terra as condições necessárias de melhoria da qualidade de vida."15

Foi em 1987, no entanto, que o primeiro conceito de sustentabilidade foi proposto pela Comissão Mundial sobre Meio Ambiente e Desenvolvimento das Nações Unidas por meio do Relatório de Bruntland - Our Common Future, o qual definiu o desenvolvimento sustentável como “(...)a capacidade de satisfazer as necessidades do presente sem comprometer a capacidade das gerações futuras de satisfazerem suas próprias necessidades".16

No entanto, tal definição não teria aplicações práticas até meados da década de 90, quando a sustentabilidade se tornou obstáculo para o avanço dos meios produtivos. Em 1992, na Cúpula da Terra, conhecida como Rio 92, foi firmado um dos primeiros acordos mundiais em que os países presentes comprometeram-se a diminuir a emissão de gases causadores do efeito estufa, sem estabelecer metas, no entanto. ${ }^{17}$ Em 1997, esse acordo foi revisto e, então, pactuado pelo nome de Protocolo de Quioto, que passou a vigorar apenas em fevereiro de 2005. Neste novo pacto os países estabeleceram que deveriam reduzir a emissão de gases,

15 SOBRE O MEIO, DECLARAÇÃO de Estocolmo. Ambiente Humano, 1972. Disponível em: http://www.silex.com.br/leis/normas/estocolmo.htm Acessado em 19 de novembro de 2018.

16 BRUNDTLAND, ONU Relatório. Nosso Futuro Comum, 1987. Disponível em: http://www.un.org/documents/ga/res/42/ares42-187.htm Acessado em 19 de novembro de 2018.

17 OLIVEIRA, Lucas Rebello de et al. Sustentabilidade: da evolução dos conceitos à implementação como estratégia nas organizações. Prod., 2012, vol.22, no.1, p.70-82 
até o período entre 2008 e 2012, em pelo menos 5\% em relação aos níveis de $1990 .^{18}$

Anos mais tarde, na Conferência das Nações Unidas sobre o Meio Ambiente e o Desenvolvimento ou Rio +10, o sociólogo britânico John Elkington apresentou um estudo que resultou na criação do Tripé da Sustentabilidade - Triple Bottom Line -, o qual considera três pilares para o alcance da sustentabilidade: o planeta, as pessoas e o lucro. 0 primeiro pilar refere-se ao cuidado para com o meio ambiente, e o meio mais eficiente de produzir, sem causar-lhe danos permanentes; o segundo pilar relaciona-se à função social da produção e do meio ambiente, estabelecendo ações que viabilizem o trabalho e suas respectivas garantias; 0 terceiro pilar tem caráter econômico, buscando investimentos viáveis e atraentes aos empreendedores. ${ }^{19} \mathrm{O}$ estudo foi desenvolvido a partir do diagnóstico da necessidade de promover uma gestão sustentável mais eficiente nas empresas, mantendo produtividade, mas protegendo o meio ambiente e o capital humano empregado.

$\mathrm{Na}$ Rio +20 , foi assinado o pacto denominado $O$ futuro que queremos. No referido documento, dentre outros compromissos, os países signatários reconheceram a necessidade de promover o desenvolvimento sustentável por meio de ações de proteção ao meio ambiente, estímulo de empreendimentos que tenham uma gestão sustentável, e promover o crescimento econômico de seus países sem agregar maiores danos ao planeta, mas objetivando refrear aqueles já causados.

Reconhecemos que a erradicação da pobreza, mudar o insustentável e promover padrões de consumo e

18 MOREIRA, Helena Margarido; Giometti, Analúcia Bueno dos Reis. Protocolo de Quioto e as possibilidades de inserção do Brasil no Mecanismo de Desenvolvimento Limpo por meio de projetos em energia limpa. Contexto Internacional. Pontifícia Universidade Católica do Rio de Janeiro, Instituto de Relações Internacionais, v. 30, n. 1, p. 9-47, 2008.

19 OLIVEIRA, Lucas Rebello de et al. Sustentabilidade: da evolução dos conceitos à implementação como estratégia nas organizações. Prod., 2012, vol.22, no.1, p.70-82.. 
produção sustentáveis e proteger e gerir os recursos naturais que são a base do desenvolvimento social e econômico são os principais objetivos e requisitos essenciais do desenvolvimento sustentável. Reafirmamos também que precisamos alcançar o desenvolvimento sustentável promovendo crescimento sustentável, econômico e igualitário. ${ }^{20}$

O conceito de sustentabilidade não é algo consolidado ainda. Há autores que definem a sustentabilidade como um intento final e que o desenvolvimento sustentável seria o caminho para alcançá-la. ${ }^{21}$ Outros alegam que a sustentabilidade seria o resultado da comunhão de uma série de sistemas que quando interligados propiciam um desenvolvimento sustentável em todas as suas dimensões.

Cabrestré, Graziadei e Polesel Filho assim definem:

Sustentabilidade seria a relação entre os sistemas econômicos e os sistemas ecológicos na qual a vida humana continuaria indefinidamente e os efeitos das atividades humanas permaneceriam dentro de limites sem destruir a diversidade, complexidade e funções do sistema ecológico de suporte da vida. ${ }^{22}$

20 The Future we want - General Assembly of UM, 2012 - Rio +20. Disponível em <http://www.un.org/ga/search/view doc.asp?symbol=A/RES/66/288\&Lan$\mathrm{g}=\mathrm{E}>$ - Acessado em 08 de novembro de 2018 - Texto original:

"We recognize that poverty eradication, changing unsustainable and promoting sustainable patterns of consumption and production and protecting and managing the natural resource base of economic and social development are the overarching objectives of and essential requirements for sustainable development. We also reaffirm the need to achieve sustainable development by promoting sustained, inclusive and equitable economic growth (...)".

21 SARTORI, Simone; LATRONICO, Fernanda; CAMPOS, LUCILA. Sustentabilidade e desenvolvimento sustentável: uma taxonomia no campo da literatura. Ambiente \& sociedade, v. 17, n. 1, 2014.

22 CABESTRÉ, Sonia Aparecida; GRAZIADEI, Tânia Maria; POLESEL FILHO, Pedro. Comunicação estratégica, sustentabilidade e responsabilidade socioambiental: um estudo destacando os aspectos teórico-conceituais e práticos. Conexão-Comunicação e Cultura, v. 7, n. 13, 2008. 
Constitucionalmente, a proteção do meio ambiente, conferindo-lhe atributos de direito fundamental, está respaldada pelo art. 225, cujo texto impõe ao poder público e à coletividade o dever de defendê-lo e preservá-lo não apenas para as gerações já presentes, mas principalmente para as futuras. Ainda, o art. 170, VI propõe a "defesa do meio ambiente, inclusive mediante tratamento diferenciado conforme o impacto ambiental dos produtos e serviços e de seus processos de elaboração e prestação", como um princípio para a ordem econômica.

O conceito de desenvolvimento sustentável na Constituição Federal de 1988 decorre da interpretação sistemática dos artigos 225, caput e 170, VI, assentado que ao Estado incumbe a preservação ambiental e que a defesa do meio ambiente é também um dos princípios norteadores da ordem econômica. ${ }^{23}$

No Brasil, Juarez Freitas é um dos autores que busca contribuir com a definição teórica do princípio da sustentabilidade, identificando suas distintas dimensões e suas implicações jurídicas. Na visão do autor, aliás, o tema da sustentabilidade deve ser tratado com urgência. Em sua obra "Sustentabilidade: direito ao futuro" - lançada em 2016, o autor prenuncia que "a espécie humana corre real perigo" por considerar que, mesmo o planeta não sendo extinto, a humanidade não conseguirá manter-se a salvo de si mesma, pois seus hábitos irrefreáveis de maus tratos ao meio ambiente que levaram a Terra à crise ambiental em que se encontra, acabarão por impedir sua permanência aqui. Há que se dar razão para o autor, afinal, segundo suas palavras:

23 B823 Brasil. Advocacia-Geral da União (AGU). Consultoria-Geral da União. Implementando licitações sustentáveis na Administração Pública Federal / Teresa Villac, Marcos Weiss Bliacheris. Brasília: AGU, 2013. 60 p. 
(...) A sustentabilidade não pode ser considerada tema efêmero ou de ocasião, mas prova viva da emergência de racionalidade dialógica, interdisciplinar, criativa, antecipatória, medidora de consequências (diretas e indiretas) e aberta. ${ }^{24}$

Juarez Freitas aprofunda-se no tema conceituando sustentabilidade como:

Princípio constitucional que determina, com eficácia direta e imediata, a responsabilidade do Estados e da sociedade pela concretização solidária desenvolvimento material e imaterial, socialmente inclusivo, durável e equânime, ambientalmente limpo, inovador, ético e eficiente, no intuito de assegurar, preferencialmente de modo preventivo e precavido, no presente e no futuro, o direito ao bem-estar. ${ }^{25}$

Em 1992, durante a Rio 92, o economista polonês Ignacy Sachs, defendeu a existência de 5 dimensões da sustentabilidade, as quais foram aprimoradas com o tempo, tendo em vista a mudança social desde à época. Segundo Sachs, a pluralidade dimensional seria dividida entre cultura, economia, espaço, sociedade e ecologia.

Freitas $^{26}$, apesar de concordar com a quantidade de dimensões, defende outros vieses para as mesmas, elencando-as em dimensões social, ética, jurídico-política, econômica e ambiental, resumidas a baixo:

(a) Dimensão social da sustentabilidade: albergam-se nessa dimensão os direitos fundamentais sociais. Nesse sentido, o autor

24 FREITAS, Juarez. Sustentabilidade: direito ao futuro / Juarez Freitas.3 ed. Belo Horizonte: Fórum, 2016. p. 31.

25 Ibid., p. 59.

26 Ibid., $61-76$. 
exemplifica a proteção dos idosos contra desamparo e exclusão por conta de idade; o direito à moradia, o qual necessita de regularização fundiária; o direito à educação de qualidade, cujas escolas necessitam reavaliar as competências ensinadas atualmente, mas que por falta de investimento e interesse, acabam por repassar os conhecimentos habituais, apenas para desafogar o sistema educacional;

(b) Dimensão ética da sustentabilidade: não se pode confundir essa dimensão com o moralismo estrito. Refere-se ao dever ético de não apenas deixar de causar mal ao meio ambiente e aos seres vivos em geral, mas proporcionar-lhes bem-estar. "Procura a universalização do bem-estar duradouro e da restauração do equilíbrio dinâmico";

(c) Dimensão ambiental da sustentabilidade: essa dimensão se preocupa em garantir "o direito das gerações atuais, sem prejuízo das futuras ao ambiente lindo e saudável". Trata-se de não apenas evitar a degradação ambiental, mas encontrar soluções para contornar a crise ambiental e proporcionar à humanidade maior tempo de vida na Terra;

(d) Dimensão econômica da sustentabilidade: percebe-se nessa dimensão, o cuidado para com a equidade, o combate ao desperdício, a gestão eficiente e eficaz de recursos públicos e privados. Preocupação presente também no que tange a reestruturação do estilo de vida dos seres humanos, alteração dos padrões de consumo e produção a fim de evitar a escassez acelerada de recursos naturais tão preciosos. Fala-se em gastar bem, em vez de gastar mais, concluindo-se que nem sempre o menos oneroso tem maior durabilidade ou eficiência; 
(e) Dimensão jurídico-política da sustentabilidade: a sustentabilidade, nesta dimensão, deixa de ser vista apenas como um ideal a ser alcançado por meio do desenvolvimento sustentável, mas também, e talvez, principalmente, como um direito: o direito ao futuro. "Apresenta-se como dever constitucional de proteger a liberdade de cada cidadão (titular de cidadania ambiental ou ecológica) (...)". Albergam-se aqui não apenas os direitos dos seres humanos, mas de todos os seres vivos, proibindo qualquer tipo de crueldade contra eles. Há atenção para com os "direitos relativos ao bem-estar duradouro", destacados os seguintes, elencados como fundamentais pelo autor: direito à longevidade digna; direito à alimentação sem excesso e carências; direito ao ambiente limpo; direito à educação de qualidade; direito à democracia preferencialmente; direito à informação livre e de conteúdo qualificado; direito ao processo judicial e administrativo com desfecho tempestivo; direito à segurança; direito à renda oriunda de trabalho decente; direito à boa administração pública; direito à moradia digna e segura.

Recentemente, Sachs acrescentou à sua lista mais 3 dimensões: política nacional, política internacional e ambiental. Percebe-se porém que, em termos de conteúdo, referidas dimensões muito se parecem com o que descreveu Freitas em sua obra.

Merece destaque, também, a posição defendida por Rammê, para quem a sustentabilidade, muito embora possua múltiplas dimensões, possui um núcleo duro, de vocação ecológica, consubstanciado na imposição de limites ecológicos ao desenvolvimento. Ademais, o referido autor, no mesmo sentido defendido por Freitas, destaca que a sustentabilidade "assume um caráter normativo cogente em nosso sistema, em razão da sua positivação implícita no texto constitucional (CF, artigos 3ํㅜ, 170 inciso VI e 225)."27

27 RAMMÊ, Rogério Santos. 0 dever fundamental ecológico e a proteção dos serviços ecossistêmicos. Curitiba: Editora Prismas, 2018, p. 190-191. 
Destaca-se, ainda, que o caráter constitucional do princípio da sustentabilidade também é reconhecido pela jurisprudência do Supremo Tribunal Federal:

O princípio do desenvolvimento sustentável, além de impregnado de caráter eminentemente constitucional, encontra suporte legitimador em compromissos internacionais assumidos pelo Estado brasileiro e representa fator de obtenção do justo equilíbrio entre as exigências da economia e da ecologia, subordinada, no entanto, a invocação desse postulado, quando ocorrente situação de conflito entre valores constitucionais relevantes, a uma condição inafastável, cuja observância não comprometa nem esvazie o conteúdo essencial de um dos mais significativos Direitos Fundamentais: o direito à preservação do meio ambiente, que traduz bem de uso comum da generalidade das pessoas, a ser resguardado em favor das presentes e futuras gerações. (STF, ADI n. 3.540-MC, Rel. Min. Celso de Mello. DJ 3/2/2006).

Em que pese, a sustentabilidade seja conceito que se relacione com a realidade vivida pela sociedade e pelos seres vivos em geral, é possível fazer algumas afirmações atemporais: a) o desenvolvimento sustentável é o processo e a sustentabilidade, o propósito; b) a sustentabilidade a ser alcançada não remete apenas ao meio ambiente, mas à sociedade em geral, considerando-se sua economia, cultura, justiça e estilo de vida; c) apesar de aparentemente utópica, alcançar a sustentabilidade depende muito mais da vontade do que da capacidade do Estado ou do particular; d) ter um planeta sustentável, com uma população que almeja a sustentabilidade, significa maior tempo de vida na Terra, não apenas degradando seus recursos, mas renovando-os. 


\section{AS LICITAÇÕES NO DIREITO BRASILEIRO APÓS A INCLUSÃO DA SUSTENTABILIDADE COMO PRINCÍPIO NORTEADOR}

Um dos atos administrativos mais importantes, e que depende em grande parte da boa administração para o seu sucesso, é a licitação: processo administrativo com o objetivo de realizar contratos administrativos pertinentes a obras, serviços, inclusive de publicidade, compras, alienações e locações no âmbito dos Poderes da União, dos Estados, do Distrito Federal e dos Municípios.

A Lei 8.666, de 21 de junho de 1993, regulamenta o Art. 37 inciso XXI da Constituição Federal de 1988 no que concerne às aquisições dos bens e serviços necessários à Administração Pública com o objetivo de atingir a sua finalidade, ou seja, o bem- estar da coletividade.

Para Marçal Justen Filho ${ }^{28}$ a licitação é um procedimento administrativo que objetiva selecionar a proposta de contratação mais vantajosa para a Administração, assegurando-se a ampla participação dos interessados, observados os requisitos legais exigidos. Ademais, o autor também define que os contratos que a Administração Pública celebra devem preceder de licitação, ressalvados os casos em que a necessidade de dispensa e de inexigibilidade seja cogente, como na contratação direta. ${ }^{29}$

No mesmo sentido, DI PIETRO ${ }^{30}$ caracteriza licitação como:

O procedimento Administrativo pelo qual um ente público, no exercício da função administrativa, abre a todos os interessados, que se sujeitem às condições fixadas no instrumento convocatório, a possibilidade de formularem propostas dentre as quais selecionará e aceitará a mais conveniente para a celebração do contrato.

28 JUSTEN FILHO, Marçal. Comentários à Lei de Licitações e Contratos administrativos. 15a ed. São Paulo: Dialética, 2012. p.11.

29 Ibid. p. 20

30 DI PIETRO, Maria Sylvia Zanella. Direito administrativo. 25. ed. São Paulo, SP: Atlas, 2012. ISBN 978-85-224-6920-8. p. 225 
Maffini complementa a definição afirmando que a licitação é um conjunto de atos administrativos que resultam em um processo administrativo que tem por finalidade obter as propostas mais vantajosas à Administração Pública, "com vistas à celebração de vínculos jurídicos contratuais junto a terceiros, particulares ou não". ${ }^{31}$

Quanto à afirmação da contratação mais vantajosa, é imprescindível analisar do que realmente se trata esta "vantajosidade". 0 art. $3^{\circ}$ da Lei 8.666/93, cuja redação foi modificada pela Lei 12.349/2010 prevê:

Art. $3^{\circ}$ A licitação destina-se a garantir a observância do princípio constitucional da isonomia, a seleção da proposta mais vantajosa para a administração e a promoção do desenvolvimento nacional sustentável e será processada e julgada em estrita conformidade com os princípios básicos da legalidade, da impessoalidade, da moralidade, da igualdade, da publicidade, da probidade administrativa, da vinculação ao instrumento convocatório, do julgamento objetivo e dos que lhes são correlatos.

Percebe-se o friso para a promoção do desenvolvimento nacional sustentável nesta nova redação, haja vista que não mais se pode falar em vantajosidade sem resguardar todas as considerações possíveis ao meio ambiente e sua proteção. Ademais, além da proteção do meio ambiente, imperativa é a promoção da sustentabilidade no âmbito social para que todos os cidadãos consigam visualizar em seu cotidiano a importância da utilização de recursos sustentáveis e que lhes trarão resultados mais efetivos a longo prazo.

Nas palavras de Justen Filho ${ }^{32}$ sobre a escolha mais vantajosa:

31 MAFFINI, Rafael. Elementos de direito administrativo. Porto Alegre: Livraria do Advogado, 2016. p. 153.

32 JUSTEN FILHO, Marçal. Comentários à lei de licitações e contratos administrativos. 14. ed. São Paulo: Dialética, 2012. p. 56. 
A maior vantagem apresenta-se quando a Administração assumir o dever de realizar a prestação menos onerosa e o particular se obrigar a realizar a melhor e mais completa prestação. Configura-se, portanto, uma relação custo-benefício. A maior vantagem corresponde à situação de menor custo e maior benefício para a Administração.

Neste sentido, Juarez Freitas afirma que as licitações em todos as esferas públicas têm de incorporar os critérios da sustentabilidade para ponderar, motivadamente, os custos e benefícios sociais, ambientais e econômicos. "Apenas assim, será aferida a real vantagem para a Administração Pública, para além das avaliações centradas nos custos de curto prazo, distorcidos e unidimensionais". ${ }^{33}$

Finger $^{34}$ conclui ainda que:

(...) o exercício da função administrativa, especialmente no campo das licitações e contratações administrativas, necessita ser ampliado para além do direito administrativo, constituindo-se também como um instrumento de regulação econômica impregnado da ética socioambiental, sem a qual o compromisso com o postulado constitucional do desenvolvimento nacional sustentável restará relegado à inocuidade.

A seguir é apresentado um breve comparativo entre a redação antiga da Lei 8.666/93 e a nova redação dada pela Lei 12349/10, permitindo melhor visualização das inovações trazidas, salientando que as principais inovações concentram-se no art. 3ํㅡ da Lei 8.666/93.

33 FREITAS, Juarez. Sustentabilidade: direito ao futuro / Juarez Freitas.3 ed. Belo Horizonte: Fórum, 2016. p. 245

34 FINGER, Ana Cláudia. Licitações sustentáveis como instrumento de política pública na concretização do direito fundamental ao meio ambiente sadio e ecologicamente equilibrado. A\&C-Revista de Direito Administrativo \& Constitucional, v. 13, n. 51, p. 121-153, 2013. 
Já no caput do referido artigo é possível visualizar uma mudança considerável: Na redação antiga, a destinação das licitações era apenas garantir o princípio constitucional da isonomia e da seleção da proposta mais vantajosa. Com a nova redação, além de garantir o princípio da isonomia e da vantajosidade, o legislador preocupou-se em incluir a promoção do desenvolvimento nacional sustentável como requisito para a escolha da melhor proposta do pregão licitatório.

Ademais, foi incluído no artigo em comento o parágrafo $5^{\circ}$, o qual estabelece de antemão que poderá ser estendida a margem de preferência produtos manufaturados e para serviços nacionais que atendam a normas técnicas brasileiras. 0 intuito do legislador com essa inclusão foi realmente de promover ações que busquem o desenvolvimento sustentável do país, e nesse sentido, não poderia haver melhor movimento do que prestigiar o mercado brasileiro em detrimento das empresas estrangeiras, respeitados os devidos limites constitucionais.

Já no parágrafo $8^{\circ}$ do artigo $3^{\circ}$, o legislador previa o estabelecimento de margens de preferência para produtos manufaturados ou para serviços nacionais que resultassem em desenvolvimento e inovação tecnológica realizados no País. Esta redação foi totalmente alterada em razão da inclusão do parágrafo $5^{\circ}$, acima referido. Neste novo texto, procurou-se limitar a margem de preferência em função do preço dos produtos brasileiros em relação aos estrangeiros, o qual foi estabelecido em um máximo de $25 \%$. Dessa forma, garante-se o tratamento desigual dos desiguais, mas respeita-se o princípio constitucional da isonomia quando extrapolado o limite imposto.

Sobre esse tratamento possivelmente desigual atribuído aos produtos nacionais em detrimento dos importados, Sampaio ${ }^{35}$ afirma:

35 SAMPAIO, Ricardo Alexandre. A nova Lei no 8.666/93. A Lei no 12.349/10 e a indução de políticas públicas para promover o desenvolvimento nacional sustentável. Revista Jus Navigandi, ISSN 1518-4862, Teresina, ano 16, n. 2813, 15 mar. 2011. Disponível em: <https://jus.com.br/artigos/18687>. Acesso em: 14 nov. 2018. 


\begin{abstract}
Ora, se a finalidade da licitação passa a ser também promover o desenvolvimento nacional sustentável, a concessão de benefícios que permitem o desenvolvimento do mercado interno se alinha a esse propósito. Trata-se, portanto, de reconhecer que os licitantes que ofertam produtos e serviços nacionais, por força de lei, não são iguais aos demais licitantes. Daí porque o fundamento para tratá-los desigualmente, na proporção da desigualdade criada pela Lei.
\end{abstract}

Freitas defende a aplicação da sustentabilidade como princípio norteador das licitações e afirma que não se trata "de simples faculdade, mas de obrigação constitucional e legal realizar licitações e contratações administrativas sustentáveis, em todos os Poderes e por todos os Poderes", e completa afirmando que é função do gestor promover o bem-estar das gerações futuras, cujos direitos fundamentais são, desde já, resguardados pelo ordenamento jurídico ${ }^{36}$.

Conforme antecipa o artigo $1^{\text {o }}$ da Lei das Licitações, a aplicação da norma é de todos os Poderes da União, dos Estado e do Distrito Federal. Assim, para ilustrar a prática dessa atualização em sua redação, serão analisados dois acórdãos publicados entre 2016 e 2017, nos quais os magistrados levaram em consideração o novo texto na aplicação da norma jurídica.

O primeiro acordão trata de denúncia formulada por Vanderleia Silva Melo em face do Pregão Presencial n.ํㅜ 31/2014 - Processo Licitatório n. - 79/2014, da Prefeitura Municipal de Conceição das Pedras/MG, cujo objeto era a aquisição de pneus, câmaras de ar e protetor de câmaras de ar novos, para manutenção dos veículos da prefeitura. A denunciante afirmava haverem irregularidades quanto ao prazo estipulado para entrega dos

36 FREITAS, Juarez. Licitações e sustentabilidade: ponderação obrigatória dos custos e benefícios sociais, ambientais e econômicos. Revista de Interesse Público, Porto Alegre, ano 13, n. 70, nov./dez. de 2011, p. 15-16 e 22. 
respectivos produtos e que isso afetaria o princípio da isonomia e da competitividade entre os licitantes.

DENÚNCIA. PREGÃO PRESENCIAL. AQUISIÇÃO DE PNEUS, CÂMARAS DE AR E PROTETOR DE CÂMARAS DE AR NOVOS. APONTAMENTOS. PRAZO EXÍGUO PARA ENTREGA DAS MERCADORIAS. RAZOABILIDADE. IMPROCEDÊNCIA. RECOMENDAÇÕES. ARQUIVAMENTO. 1. A ANÁLISE EXAURIENTE DA EXIGUIDADE OU NÃO DO PRAZO PARA ENTREGA DOS PRODUTOS OBJETO DE LICITAÇÃO DEPENDE DA PECULIARIDADE DO CASO CONCRETO, DEVENDO SER CONSIDERADA A LOCALIZAÇÃO GEOGRÁFICA DO ÓRGÃO ADQUIRENTE E A REALIDADE DO MERCADO PARA O PRODUTO OU SERVIÇO ALMEJADO. 2. EMBORA O DESGASTE COMUM DOS PNEUMÁTICOS POSSA E DEVA SER ACOMPANHADO E ESTIMADO PELA ADMINISTRAÇÃO, DE MODO A PLANEJAR SUA AQUISIÇÃO E CONSEQUENTE REPOSIÇÃO, TRATA-SE DE BENS DE CONSUMO CUJA DEMANDA DE REPOSIÇÃO NÃO RARO É IMPREVISÍVEL, SEJA EM FACE DE ACIDENTES, DA IRREGULARIDADE DO TERRENO E DA CAPILARIDADE DA MALHA RODOVIÁRIA RÚSTICA, DESPROVIDA DE PAVIMENTAÇÃO, MUITO COMUM NA MAIORIA DOS MUNICÍPIOS. 3. RECOMENDA-SE QUE, NOS PRÓXIMOS CERTAMES LICITATÓRIOS, PARA A ESCOLHA DA MELHOR FORMA DE CONTRATAÇÃO, DENTRO DOS LIMITES LEGAIS, RESGUARDEM A ISONOMIA ENTRE OS LICITANTES, A VANTAJOSIDADE PARA A ADMINISTRAÇÃO E A SUSTENTABILIDADE, A FIM DE CUMPRIR O DEVER CONSTITUCIONAL DE PRESERVAÇÃO DO MEIO AMBIENTE, NOS TERMOS DO ART. 225 DA CONSTITUIÇÃO DA REPÚBLICA E DO ART. $3{ }^{\circ}$ DA LEI N. 8.666/93. 4. É DEVER LEGAL DO GESTOR PÚBLICO DAR EFETIVIDADE AMBIENTAL (ART. 3 DA LEI N. 8.666/93)Às CONTRATAÇÕES PÚBLICAS, EM RESPEITO AO PRINCÍPIO DA PROTEÇÃO AO MEIO AMBIENTE, INSERTO NO ART. 225 DA CONSTITUIÇÃO DO BRASIL. PORTANTO, PRIVILEGIAR BENS FABRICADOS E SERVIÇOS 
PRESTADOS COM BASE EM PARÂMETROS QUE MINIMIZEM DANOS AMBIENTAIS, EXIGINDO, POR EXEMPLO, A LOGÍSTICA REVERSA PREVISTA NO INCISO III DO ART. 33 DA LEI N. 12.305/10, É RESPEITAR A CONSTITUIÇÃO, AS NORMAS INTERNACIONAIS RATIFICADAS E DEMAIS LEIS DE PROTEÇÃO AMBIENTAL, CONTEMPLANDO, DESSA FORMA, INTERESSE PÚBLICO PRIMÁRIO. (TCE-MG - DEN: 924201, Relator: CONS. SUBST. HAMILTON COELHO, Data de Julgamento: 21/06/2016, Data de Publicação: 19/09/2017)

Em que pese a denúncia não tenha sido acolhida por indícios quanto à regularidade do pregão, o magistrado demonstrou preocupação com a aplicação da norma e recomendou fortemente que nas próximas licitações o princípio da sustentabilidade seja norteador na tomada da decisão, não apenas em razão da proteção do meio ambiente como impõe o art. 225 da CF/88, mas também na escolha de bens fabricados nacionalmente e que estejam em conformidade às normas técnicas brasileiras, as quais procuram minimizar os danos ambientais.

O segundo acordão decide Mandado de Segurança impetrado pela empresa Edmilson Alves Barbosa ME, contra ato do Secretário de Administração do Estado do Piauí. O impetrante sustenta irregularidade na licitação cujo procedimento deu-se por pregão eletrônico, do tipo menor preço "por item", para aquisição de equipamentos de informática e componentes de tecnologia da informação, que atenderiam às demandas do Governo do Estado do Piauí.

MANDADO DE SEGURANÇA. POSSÍVEIS IRREGULARIDADES EM EDITAL DE LICITAÇÃO. PREGÃO ELETRÔNICO. CLÁUSULA RESTRITIVA AO CARÁTER COMPETITIVO. JUSTIFICATIVAS INSUFICIENTES PARA ELIDIR PARTE DAS IRREGULARIDADES SUSCITADAS. SEGURANÇA CONCEDIDA. 1. Em que pese a autoridade coatora ter esclarecido, quando da resposta à impugnação administrativa feita pela 
impetrante, que o edital do Pregão Eletrônico, sob o qual se insurgem os autos, sinaliza que a certificação/compatibilidade EPEAT pode ser suprida por certificação similar, tal esclarecimento não condiz com a realidade. No caso do item 3 do certame em questão, a competição potencial ficou limitada aos fabricantes de microcomputadores registrados no EPEAT com a classificação Gold, Silver ou Bronze (fls. 77 e 101 Â- Volume I), impedindo a participação da impetrante e de outros fabricantes não listados pela ferramenta de busca do EPEAT. 2. Afere-se dos autos que, dos computadores requisitados, apenas uma pequena parte estão totalmente desobrigados de possuir a certificação EPEAT. Assim sendo, a exigência de referida certificação, como única forma de atender a critérios de sustentabilidade ambiental, está em desconformidade com o art. $3^{\circ}, \S 1^{\circ}$, inciso I, da Lei no 8.666/1993 (Lei de Licitações) e com o art. $3^{\circ}$, inciso II, da Lei no ${ }^{\circ}$ 10.520/2002 (Lei do Pregão), que estabelece: "a definição do objeto deverá ser precisa, suficiente e clara, vedadas especificações que, por excessivas, irrelevantes ou desnecessárias, limitem a competição". 3. Tem-se que a exigência de critérios ambientais para aquisição de bens pela Administração Pública é razoável, porém, além da avaliação EPEAT, deveriam ter sido aceitos outros sistemas de avaliação e classificação ambiental utilizados pelo mercado de microcomputadores ou outros meios de verificação da adequação do equipamento a exigências ambientais estabelecidas no ato convocatório. A exigência de avaliação EPEAT, como única forma de atender a critérios de sustentabilidade ambiental, é excessiva e limita a competição. 4. Por todo o exposto, em desconformidade com o parecer ministerial superior, voto pela concessão da segurança pleiteada, mantendo em todos os temos a liminar concedida às fls. 207/210, para determinar a reformulação do Edital do Pregão Eletrônico no 014/2011- DLCA/SEAD, sob o qual se insurge o feito, vez que além da avaliação EPEAT, deveriam ter sido aceitos outros sistemas de avaliação 
e classificação ambiental utilizados pelo mercado de microcomputadores ou outros meios de verificação da adequação do equipamento a exigências ambientais estabelecidas no ato convocatório. (TJ-PI - MS: 201200010004962 PI 201200010004962 , Relator: Des. José Francisco do Nascimento, Data de Julgamento: 22/05/2014, Tribunal Pleno)

Neste caso concreto, o princípio da sustentabilidade foi utilizado pela administração como norteador, no entanto, não foram utilizados mecanismos suficientes para habilitação dos licitantes no pregão. Foi solicitada apenas certificação técnica internacional sobre os equipamentos, deixando-se de observar outras avaliações que poderiam ou não os caracterizar dentro dos requisitos da sustentabilidade. Dessa forma, acabou-se por ferir o princípio da isonomia e da competitividade entre os licitantes. 0 magistrado decidiu por acolher o pedido e ordenar que fosse refeito o pregão a fim de que fossem estabelecidos parâmetros diferentes e mais eficazes para classificação dentro dos critérios de sustentabilidade ambiental.

Alcançar a sustentabilidade deve ser o grande objetivo de todos, principalmente do Estado. Pensá-la como uma utopia é um grande erro, pois trata-se de uma meta cujo alcance dar-se-á por meio de um processo de desenvolvimento, cuja prática precisa ser diária e em todas as esferas, tanto pública quanto particular. Não se trata apenas de proteger o meio ambiente, evitando danos ambientais ou mudando padrões de consumo e produção. Trata-se de tomar medidas que tragam para a realidade a literalidade da palavra sustentável: "Que se consegue sustentar (manter); em que há ou pode haver sustentação"37. 0 dever do Estado, nesse sentido, é viabilizar políticas públicas que garantam a permanência das gerações presentes e futuras no planeta Terra, e que

37 Dicio - Dicionário Online de Língua Portuguesa. Disponível em < https:// www.dicio.com.br/sustentavel/>. Acessado em 15 de novembro de 2018. 
garantam seu sustento, a equidade, sua dignidade e seu direito a um meio ambiente limpo e sadio.

\section{AS LICITAÇÕES SUSTENTÁVEIS E O DIREITO FUNDAMENTAL À BOA ADMINISTRAÇÃO PÚBLICA}

Já foi visto no decorrer deste trabalho sobre a supremacia do interesse público, o poder de polícia da Administração Pública, o que seria uma boa administração, o conceito de sustentabilidade e suas dimensões e também a nova redação da Lei de Licitações. Resta agora definir se realmente as licitações sustentáveis são um mecanismo eficaz de concretização do direito fundamental à boa administração pública.

A Consultoria Legislativa da Câmara dos Deputados formulou um relatório intitulado "Marco legal das licitações e compras sustentáveis na administração pública" cujo objetivo era trazer ao público conhecimento sobre o porquê da necessidade de incluir a sustentabilidade ao texto da Lei 8.666/93. Sobre as compras sustentáveis, o relatório afirma, baseado na Cartilha da Agenda Ambiental da Administração Pública, um dos primeiros documentos indutores que estimulavam à adoção de medidas de proteção ao meio ambiente dentro do âmbito da Administração Pública, que:

Compras sustentáveis consistem naquelas em que se tomam atitudes para que o uso dos recursos materiais seja o mais eficiente possível. Isso envolve integrar os aspectos ambientais em todos os estágios do processo de compra, de evitar compras desnecessárias a identificar produtos mais sustentáveis que cumpram as especificações de uso requeridas. Logo, não se trata de priorizar produtos apenas devido a seu aspecto ambiental, mas sim considerar seriamente tal aspecto juntamente com os tradicionais critérios de especificações técnicas e preço. ${ }^{38}$

38 VALENTE, Manoel Adam Lacayo. Marco legal das licitações e compras sustentáveis na Administração Pública. Câmara dos deputados, 2011. 
O relatório também aponta a Instrução Normativa $\mathrm{n}$ o 01/2010-SLTI/MPOG de 19 de Janeiro de 2010 como sendo o grande marco legal da inclusão da sustentabilidade no contexto licitatório. A partir dele, o legislador percebeu finalmente a necessidade de não apenas instruir, mas obrigar por força de lei que políticas públicas de promoção do desenvolvimento sustentável tivessem espaço na agenda das compras públicas.

Em seu art. 1ำ a Instrução Normativa instrui que, considerando o disposto na Lei das Licitações, incluam-se critérios sustentáveis nos procedimentos de licitação:

Art. $1^{\circ}$ Nos termos do art. $3^{\circ}$ da Lei $n^{\circ}$ 8.666, de 21 de junho de 1993, as especificações para a aquisição de bens, contratação de serviços e obras por parte dos órgãos e entidades da administração pública federal direta, autárquica e fundacional deverão conter critérios de sustentabilidade ambiental, considerando os processos de extração ou fabricação, utilização e descarte dos produtos e matérias-primas.

Da mesma forma, a Justiça Federal da 3 ${ }^{\text {a }}$ Região formulou um "Manual de Licitações Sustentáveis" objetivando implementar naquela região um novo paradigma de compras, que contribua na promoção do desenvolvimento sustentável, e que estimule um maior engajamento dos envolvidos nos processos licitatórios. ${ }^{39}$

O manual explica que o gestor quando da tomada de decisão sobre o melhor produto não deve se ater ao aspecto econômico da compra, mas considerar e garantir o equilíbrio entre o impacto ambiental, a viabilidade, a competitividade e o preço, todos princípios estabelecidos pelo artigo $3^{\circ}$ da Lei 8.666/93.

39 Brasil. Tribunal Regional Federal da 3a - Região.Manual de licitações sustentáveis da Justiça Federal da 3a Região. São Paulo : Tribunal Regional Federal da 3ํㅡㄹ Região, 2016. p. 7. 
De uma maneira mais abrangente, as contratações públicas sustentáveis significam a integração sistemática dos critérios de sustentabilidade em todas as atividades e etapas da aquisição de bens, serviços e obras, independentemente da forma de contratação, trazendo importantes reflexos às demais atividades institucionais. ${ }^{40}$

Nesse novo contexto legal, a Administração Pública tem o dever de introduzir nos editais das futuras licitações sobre serviços, compras ou obras de qualquer natureza, critérios de sustentabilidade e especificações técnicas que possam classificar de forma eficiente serviços que estejam de acordo com os parâmetros de sustentabilidade ambiental previstos em lei, no entanto, sem baldar a competitividade, a isonomia entre os licitantes e a viabilidade do procedimento.

Um dos documentos mais recentes sobre as licitações sustentáveis foi escrito pela Advocacia Geral da União, lançado em 2017, e intitulado "O Manual da Advocacia Geral da União - Implementando Licitações Sustentáveis na Administração Pública Federal". Em seu texto o qual divide-se em duas partes, buscou-se em um primeiro momento contextualizar historicamente o desenvolvimento do conceito de sustentabilidade e de desenvolvimento sustentável, bem como conceituar o que seriam as licitações sustentáveis de fato. Na segunda parte, aprofundou-se o tema, analisando a nova legislação e apresentando uma espécie de cartilha para aplicação da sustentabilidade nos procedimentos licitatório em âmbito federal.

Nos quatro documentos citados, percebem-se diversas semelhanças no tocante à instrução dos agentes públicos em sua atuação dentro do processo de compras públicas, pois, em que pese a legislação seja bastante clara, se faz necessário demonstrar de forma prática quais políticas devem ser instauradas a fim

40 Ibidem p. 10 
de garantir a aplicabilidade da norma. Nota-se da mesma forma que os textos buscam tornar-se imperiosa a realidade que a Lei das Licitações procura, ou seja, trazer maior eficiência e eficácia às licitações.

Este conceito de eficiência e eficácia estão diretamente relacionados ao direito fundamental à boa administração pública, como assim conceitua Valle ao afirmar que apesar da vastidão de conteúdo da boa administração, a observância do princípio da eficiência é uma das maiores manifestações deste direito. ${ }^{41} \mathrm{No}$ mesmo sentido, Freitas afirma que trata-se de "direito fundamental à administração pública, eficiente e eficaz, proporcional, cumpridora de seus deveres, com transparência, motivação, imparcialidade e respeito à moralidade, à participação social e à plena responsabilidade por suas condutas omissivas e comissivas". ${ }^{42}$

Ora, se por definição o direito fundamental à boa administração é aquele que garanta uma Administração Pública eficiente e eficaz - que utiliza da discricionariedade apenas com a finalidade de salvaguardar os direitos da coletividade e que tem o interesse público como seu grande norteador -, as licitações sustentáveis mostram-se como uma política pública extremamente efetiva para sua concretização. Aplicar o princípio da sustentabilidade às compras públicas significa gerir melhor os recursos econômicos e naturais do país, garantir à população uma gestão mais eficiente e que propiciará às gerações presentes e futuras o resguardo de seus direitos fundamentais ao meio ambiente, à dignidade, à moradia, à justiça e à igualdade.

41 VALLE, Vanice Lírio do. Direito fundamental à boa administração, políticas públicas eficientes e a prevenção do desgoverno. Interesse Público, v. 48, p. 87-110, 2008.

42 FREITAS, Juarez. Discricionariedade administrativa e o direito fundamental à boa administração pública. São Paulo: Malheiros, 2007, p.20. 


\section{CONSIDERAÇÕES FINAIS}

Sem nenhuma pretensão de esgotar o tema, este artigo debateu uma matéria de grande relevância para o momento atual, pois, as licitações sustentáveis são, indubitavelmente, um dever de todos os Poderes do Estado que constitucionalmente encontram-se obrigados a promover o desenvolvimento sustentável da economia, da sociedade e do meio ambiente, dessa forma fomentando o crescimento de mercado de produtos e serviços que estejam adequados aos critérios de classificação de sustentabilidade.

A preservação dos recursos naturais do planeta é assunto que precisa ser debatido constantemente por todas as nações. Contudo, o mero debate não terá efetividade se não forem tomadas medidas que de fato colaborem e promovam a preservação do meio ambiente, sendo o Estado, em primeira instancia, o principal responsável pela tomada de ação. Nesse âmbito, o Brasil, signatário da maioria dos pactos internacionais de proteção ao meio ambiente e promoção do desenvolvimento sustentável, encontrou, dentro de uma área tão importante da Administração Pública, uma forma de efetivar seu papel como uma nação que protege os seus cidadãos e sobretudo o planeta em que vivem.

A preservação do meio ambiente sadio e equilibrado prevista no artigo 225 da Constituição Federal de 1988 e a promoção do desenvolvimento sustentável, o qual tem sua definição como aquele que atende às necessidades do presente, sem comprometer a capacidade de as gerações futuras atenderem as suas próprias necessidades, bem como o equilíbrio de questões de ordem social e econômica, as quais balizam o conceito de sustentabilidade, quando interligadas e inseridas no contexto das licitações públicas tornam este ato administrativo tão importante como um mecanismo prático e que traduz de forma clara o direito fundamental à administração proba.

A falta de preparo e conhecimento por parte dos agentes públicos responsáveis pelos procedimentos licitatórios mostra- 
-se como uma das grandes dificuldades na realização das compras públicas sustentáveis, pois não são tão claros na lei quais os critérios e especificações técnicas a serem avaliados quando da habilitação dos licitantes. Por isso da criação constante de manuais, cartilhas e resoluções que satisfaçam essa necessidade de conhecimento sobre o tema. Outro fator que impede a concretização do pregão é o mercado que ainda está se habituando à nova realidade das licitações, tendo em vista que a nova redação tem menos de dez anos.

A grande questão debatida no decorrer do estudo foi se, de fato, as licitações sustentáveis seriam um mecanismo eficaz na concretização do direito fundamental à boa administração. Restou demonstrado que a boa administração diz respeito à melhor gestão possível da Administração Pública, considerando seus recursos financeiros e de capital humano. A melhor gestão significa gerir de forma eficaz e eficiente todas as áreas e setores da Administração, tanto na organização como no procedimento. Já as licitações sustentáveis mostraram-se um meio de aplicar eficientemente o disposto nos artigos da Constituição Federal no que tange à promoção do desenvolvimento sustentável e ao direito ao meio ambiente sadio, pois a partir dela a valorização de produtos que respeitem o meio ambiente e considerem a sustentabilidade um modelo de produção ficou mais evidenciada.

Conclui-se, que a hipótese inicialmente formulada restou confirmada. 0 direito fundamental à boa administração encontra, sim, albergue nas licitações sustentáveis a fim de se concretizar, pois por meio delas o gestor público consegue alcançar o princípio da sustentabilidade e garantir à população das gerações presentes e das futuras que seus direitos fundamentais serão preservados.

\section{REFERÊNCIAS BIBLIOGRÁFICAS}

ALENCASTRO, Maria Alice Cruz; DA SILVA, Edson Vicente; LOPES, Ana Maria D.'́vila. Contratações sustentáveis na administração pública 
brasileira: a experiência do Poder Executivo federal. Revista de Administração Pública, v. 48, n. 1, p. 207-236, 2014.

B823 Brasil. Advocacia-Geral da União (AGU). Consultoria-Geral da União. Implementando licitações sustentáveis na Administração Pública Federal / Teresa Villac, Marcos Weiss Bliacheris. Brasília: AGU, 2013. 60 p. Disponível em: <https://redeagu.agu.gov.br/PaginasInternas.asp $\mathrm{x}$ ?idConteudo $=275932$ \&idSite $=1104 \&$ aberto $=\&$ fechado $>$ Acessado em 15 de novembro de 2018.

Brasil. Tribunal Regional Federal da 3a Região. Manual de licitações sustentáveis da Justiça Federal da $3^{a}$ Região. São Paulo: Tribunal Regional Federal da 3ํㅡㄹ Região, 2016. 27p. Disponível em: <http://www. trf3.jus.br/documentos/adeg/Socioambiental/PLS/Manual_de_Licitacoes_Sustentaveis-diagramado.pdf> Acessado em 15 de novembro de 2018.

BRUNDTLAND, ONU Relatório. Nosso Futuro Comum, 1987. Disponível em: http://www.un.org/documents/ga/res/42/ares42-187.htm Acessado em 19 de novembro de 2018.

CABESTRÉ, Sonia Aparecida; GRAZIADEI, Tânia Maria; POLESEL FILHO, Pedro. Comunicação estratégica, sustentabilidade e responsabilidade socioambiental: um estudo destacando os aspectos teórico-conceituais e práticos. Conexão-Comunicação e Cultura, v. 7, n. 13, 2008.

CARVALHO FILHO, José do Santos. Manual de direito administrativo / José dos Santos Carvalho Filho. 27. ed. rev., ampl. e atual. São Paulo, SP: Atlas, 2014. 1285p..

DE AGUIAR, Mariane Rodrigues Volz et al. Licitações públicas: os desafios da sustentabilidade ambiental, 2013. Disponível em: <http:// www.conhecer.org.br/enciclop/2013a/ciencias\%20sociais/licitacoes. pdf> Acessado em 14 de novembro de 2018.

OLIVEIRA, Lucas Rebello de et al. Sustentabilidade: da evolução dos conceitos à implementação como estratégia nas organizações. Prod., 2012, vol.22, no.1, p.70-82.

DI PIETRO, Maria Sylvia Zanella. Direito administrativo. 25. ed. São Paulo, SP: Atlas, 2012. 932 p. ISBN 978-85-224-6920-8.

FEIL, Alexandre André; SCHREIBER, Dusan. Sustentabilidade e desenvolvimento sustentável: desvendando as sobreposições e alcances de seus significados. Cadernos EBAPE. BR, v. 15, n. 3, p. 667-681, 20 
FINGER, Ana Cláudia. Licitações sustentáveis como instrumento de política pública na concretização do direito fundamental ao meio ambiente sadio e ecologicamente equilibrado. A\&C-Revista de Direito Administrativo \& Constitucional, v. 13, n. 51, p. 121-153, 2013.

FREITAS, Juarez. Discricionariedade administrativa e o direito fundamental à boa administração pública. São Paulo: Malheiros, 2007.

FREITAS, Juarez. Sustentabilidade: direito ao futuro / Juarez Freitas.3 ed. Belo Horizonte: Fórum, 2016. 347 p. ISBN 978-85-450-0119-5.

FREITAS, Juarez. Discricionariedade administrativa e o direito fundamental à boa administração pública. São Paulo, SP: Malheiros, 2007. 143 p. ISBN 978-85-7420-818-3.

FREITAS, Juarez. 0 controle dos atos administrativos e os princípios fundamentais. 4. ed. ref. e ampl. São Paulo, SP: Malheiros, 2009. 512 p. ISBN 978-85-7420-950-0.

FREITAS, Juarez. Políticas Públicas, Avaliação de Impactos e o Direito Fundamental à Boa Administração. Sequência (Florianópolis), Florianópolis , n. 70, p. 115-133.

FREITAS, Juarez. Licitações e sustentabilidade: ponderação obrigatória dos custos e benefícios sociais, ambientais e econômicos. Revista de Interesse Público, Porto Alegre, ano 13, n. 70, nov./dez. de 2011.

FREITAS, Vladimir Passos de. Direito administrativo e meio ambiente. 3. ed. Curitiba, PR: Juruá, 2003. 209 p. ISBN 85-7394-828-0.

GARCIA, Flávio Amaral; RIBEIRO, Leonardo Coelho. Licitações públicas sustentáveis. Revista de Direito Administrativo, v. 260, p. 231, 2012.

GUIMARÃES, Roberto Pereira. Desenvolvimento sustentável: da retórica à formulação de políticas públicas. In: BECKER, Bertha K.; MIRANDA, Mariana (org.). A geografia política do desenvolvimento sustentável. Rio de Janeiro: UFRJ, 1997

IPIRANGA, Ana Silva Rocha; GODOY, Arilda Schmidt; BRUNSTEIN, Janette. Introdução. RAM, Rev. Adm. Mackenzie (Online), São Paulo, v. 12, n. 3, p. 13-20, June 2011.

JUSTEN FILHO, Marçal. Curso de direito administrativo. 4. ed. rev. atual. São Paulo, SP: Saraiva, 2009. 851 p. ISBN 978-85-02-07616-7.

JUSTEN FILHO, Marçal. Comentários à Lei de Licitações e Contratos administrativos. 15a ed. São Paulo: Dialética, 2012. 
MEDAUAR, Odete. Direito administrativo moderno. 18. ed. rev. e atual. São Paulo, SP: RT, 2014.

MAFFINI, Rafael. Elementos de direito administrativo. Porto Alegre: Livraria do Advogado, 2016.

MEIRELLES, Hely Lopes; ALEIXO, Délcio Balestero; BURLE FILHO, José Emmanuel. Direito administrativo brasileiro. 40. ed. São Paulo, SP: Malheiros, 2013.

MEllo, Celso Antônio Bandeira de. Curso de direito administrativo. 31. ed. São Paulo, SP: Malheiros, 2014.

MOREIRA NETO, Diogo de Figueiredo. Curso de direito administrativo: parte introdutória, parte geral e parte especial. 16. ed. rev. e atual. Rio de Janeiro, RJ: Forense, 2014.

MOREIRA, Helena Margarido; Giometti, Analúcia Bueno dos Reis. Protocolo de Quioto e as possibilidades de inserção do Brasil no Mecanismo de Desenvolvimento Limpo por meio de projetos em energia limpa. Contexto Internacional. Pontifícia Universidade Católica do Rio de Janeiro, Instituto de Relações Internacionais, v. 30, n. 1, p. 9-47, 2008. Disponível em: <http://hdl.handle.net/11449/8798> Acessado em 15 de novembro de 2018.

RAMMÊ, Rogério Santos $\mathbf{O}$ dever fundamental ecológico e a proteção dos serviços ecossistêmicos. Curitiba: Editora Prismas, 2018.

SAMPAIO, Ricardo Alexandre. A nova Lei no 8.666/93. A Lei no 12.349/10 e a indução de políticas públicas para promover o desenvolvimento nacional sustentável. Revista Jus Navigandi, ISSN 1518-4862, Teresina, ano 16, n. 2813, 15 mar. 2011. Disponível em: <https://jus.com.br/artigos/18687>. Acesso em: 14 nov. 2018.

SARTORI, Simone; LATRONICO, Fernanda; CAMPOS, LUCILA. Sustentabilidade e desenvolvimento sustentável: uma taxonomia no campo da literatura. Ambiente \& sociedade, v. 17, n. 1, 2014.

SOBRE O MEIO, DECLARAÇÃO de Estocolmo. Ambiente Humano, 1972. Disponível em: <http://www.silex.com.br/leis/normas/estocolmo.htm> Acessado em 19 de novembro de 2018.

The Future we want - General Assembly of UM, 2012 - Rio +20. Disponível em: <http://www.un.org/ga/search/view_doc.asp?symbol=A/ RES/66/288\&Lang=E $>$ - Acessado em 8 de novembro de 2018. 
VALLE, Vanice Lírio do. Direito fundamental à boa administração, políticas públicas eficientes e a prevenção do desgoverno. Interesse Público, v. 48, p. 87-110, 2008.

VALENTE, Manoel Adam Lacayo. Marco legal das licitações e compras sustentáveis na Administração Pública. Câmara dos deputados, 2011. Disponível em: <http://www2.camara.leg.br/atividade-legislativa/estudos-e-notas-tecnicas/publicacoes-da-consultoria-legislativa/areas-da-conle/tema1/2011_1723.pdf> Acessado em 15 de novembro de 2018. 